\title{
Real-life experience of using brinzolamide/brimonidine fixed drop combination in a tertiary glaucoma centre
}

\author{
Péter Kóthy (D) Gábor Holló $\mathbb{B}$
}

Received: 4 March 2019/Accepted: 10 October 2019/Published online: 24 October 2019

(C) The Author(s) 2019

\begin{abstract}
Purpose To investigate the intraocular pressure (IOP)-lowering efficacy and tolerance of brinzolamide/brimonidine fixed combination (BBFC) under real-life conditions in a tertiary glaucoma centre.

Methods Medical records of all ocular hypertensive and open-angle glaucoma patients $(n=52)$ treated with BBFC were retrospectively analysed.

Results Thirty-nine patients had primary open-angle, 6 exfoliative, 2 pigment, 1 normal tension and 1 juvenile open-angle glaucoma and 3 ocular hypertension. The prior therapy was a prostaglandin analogue (PG) $(n=4)$, PG/timolol $(n=20), \mathrm{PG} /$ timolol and topical carbonic anhydrase inhibitor (CAI; $n=19$ ), timolol/CAI $(n=1)$, PG and CAI $(n=4)$, timolol/ pilocarpine and PG $(n=1)$, timolol/brimonidine and PG $(n=1)$ and timolol/brimonidine, PG and CAI $(n=2)$. These were simplified to PG/timolol and BBFC $(n=41)$, PG and BBFC $(n=9)$, timolol and $\operatorname{BBFC}(n=1)$ and timolol/pilocarpine, PG and BBFC $(n=1)$. The IOP on the study eyes was $21.2 \pm 3.7 \mathrm{mmHg}$ before and $16.9 \pm 2.6$, $16.0 \pm 2.2,17.6 \pm 3.1$ and $18.0 \pm 3.1 \mathrm{mmHg}$ after the introduction of BBFC at month 1, 3, 6 and 12, respectively ( $p<0.0003$ for all time points compared to baseline, $p=1.0$ for all other comparisons). Thirty-
\end{abstract}

P. Kóthy · G. Holló $(\bowtie)$

Department of Ophthalmology, Semmelweis University,

Mária u. 39, Budapest 1085, Hungary

e-mail: hollo.gabor@med.semmelweis-univ.hu one patients (59.6\%) experienced no adverse event, 17 $(32.7 \%)$ reported ocular and $6(11.5 \%)$ systemic adverse events. BBFC therapy was terminated on 27 patients $(51.9 \%)$ : on $19(36.5 \%)$ due to adverse events and on $8(15.4 \%)$ due to insufficient IOP reduction.

Conclusion In real-life practice, the introduction of $\mathrm{BBCF}$ allows significant and clinically meaningful IOP reduction and therapy simplification in glaucoma patients requiring complex medication, but in more than one third of the patients it is not tolerated due to adverse events.

Keywords Brinzolamide/brimonidine fixed combination - Glaucoma - Intraocular pressure reduction · Real-life clinical investigation - Adverse events - Topical glaucoma medication

\section{Introduction}

Topical medication remains the most commonly applied treatment option in glaucoma [1]. In the long run, many glaucoma patients require more than one active intraocular pressure (IOP)-lowering molecule to reach the target IOP and prevent glaucomatous progression, and a considerable subset of the patients requires complex medication comprising more than two active IOP-lowering molecules [1-4]. Use of topical fixed dose combinations (FCs) reduces the 
number of daily eye drop instillations and therefore supports adherence $[1,5,6]$. However, in almost all IOP-lowering FCs, one of the active ingredients is a beta receptor blocker (timolol), which makes it impossible to combine the timolol-containing FCs. The FC of brinzolamide $1 \%$ and brimonidine $0.2 \%$ (BBFC), manufactured in suspension formulation, is the first IOP-lowering FC without a beta receptor blocker. This characteristics allow BBFC to be used not only as a stand-alone therapy but also as part of complex medication involving timolol, prostaglandin analogues (PGs) and their combinations.

In the randomized prospective parallel group studies, the IOP-lowering efficacy of stand-alone BBFC ranged between 5.4 and $9.3 \mathrm{mmHg}$ in openangle glaucoma and ocular hypertension [7-15]. The relative IOP reduction ranged between approximately 25\% (trough efficacy) and 35\% (peak efficacy). BBFC is additive to PG monotherapy. When added to a PG monotherapy, the additional IOP reduction was 3.0 to $5.6 \mathrm{mmHg}$ (13.0 to $16.5 \%)$ greater than that found when vehicle alone was added to the same PG monotherapy [16-18].

While short-term prospective studies are relatively numerous, there have been few long-term real-life clinical investigations, which can inform clinicians about IOP reduction and tolerance of BBFC in cases not eligible for inclusion in prospective randomized studies. In a recent investigation, it was shown that $\mathrm{BBCF}$ is effective both in treatment naive and under topical treatment of normal tension glaucoma eyes during a 18-month period [19]. In another retrospective investigation, IOP reduction 2 to 17.5 month after the introduction of BBFC was evaluated on 76 under treatment open-angle glaucoma patients [20]. The mean IOP reduction was $2.76 \mathrm{mmHg}$, but the authors provided no information on the previous therapies and the treatment changes made at the time of the introduction of BBFC in the treatment. To our knowledge, no long-term real-life investigation has been published on the use of BBFC in difficult to control high-pressure open-angle glaucoma. Therefore, in our current investigation, we retrospectively analysed the data of all open-angle glaucoma and ocular hypertensive patients treated with BBFC between February 2016 and June 2018 in our clinical unit, a European tertiary glaucoma centre.

\section{Materials and methods}

A retrospective analysis of the electronic records was conducted. All open-angle glaucoma and ocular hypertensive patients treated with at least one drop of BBFC in the Glaucoma Centre of Semmelweis University between February 2016 (when BBCF became available in Hungary) and June 2018 were included in the analysis. The research protocol was approved by the Institutional Review Board for Human Research of Semmelweis University, Budapest. All applicable institutional and governmental regulations concerning the ethical use of patients' data were followed.

All patients used BBFC twice daily at intervals of approximately $12 \mathrm{~h}$. Data of one eye per person were analysed. When both eyes of a patient were treated with BBFC, the eye with the higher IOP prior to the introduction of BBFC was selected for the study. The analysed parameters comprised the clinical diagnosis, age, sex, best corrected visual acuity, refractive error (spherical equivalent), central corneal thickness, Octopus perimetry mean defect, vertical cup/disc ratio, treatment prior to the introduction of $\mathrm{BBFC}$, treatment containing BBFC, IOP on medication prior to the introduction of BBFC, IOP at 1, 3, 6 and 12 months and in the last visit on topical medication containing BBFC, adverse events related to BBFC, duration of BBFC therapy before the adverse events appeared and reasons for BBFC termination. The IOP measurements were all made between 8 a.m. and 12 noon. When IOP phasing was done, the morning IOP values were averaged for the between-visit comparisons.

\section{Statistics}

The baseline demographics data are presented as mean and SD. Due to the considerable differences in the number of eyes between the various follow-up time points, the paired $t$ test with Bonferroni correction was used for the comparison of the IOP values between the various follow-up time points. Bonferroni corrected $p$ values less than 0.05 were considered as statistically significant. 


\section{Results}

Fifty-two patients were identified. Precise IOP measurement was not possible in two patients due to poor cooperation. These eyes were not included in the efficacy analysis. The length of the follow-up period on therapy containing BBFC was $12.8 \pm 9.7$ months. The maximal follow-up was 28 months. The age of the patients was $69.3 \pm 10.2$ years. Twenty-five patients were females and 27 were males. The best corrected visual acuity was $0.8 \pm 0.3$; the refractive error $-0.7 \pm 2.4$ dioptres; and the central corneal thickness $538.5 \pm 29.8 \mu \mathrm{m}$. Thirty-nine patients had primary open-angle, 6 exfoliative, 2 pigment, 1 normal tension and 1 juvenile open-angle glaucoma, and 3 patients had ocular hypertension on the study eye. The Octopus perimetry visual field mean defect was $12.8 \pm 7.7 \mathrm{~dB}$, and the vertical cup/disc ratio was $0.9 \pm 0.16$ (Table 1).

The therapy prior to the introduction of $\mathrm{BBFC}$ was a PG on 4 eyes, a PG/timolol FC on 20 eyes, a PG/timolol FC and a topical carbonic anhydrase inhibitor (CAI) on 19 eyes, a timolol/CAI FC on 1 eye, a PG and a CAI on 4 eyes, a timolol/pilocarpine FC and a PG on 1 eye, a timolol/brimonidine FC and a PG on 1 eye, and a timolol/brimonidine FC, a PG and a CAI on 2 eyes (Table 2). At the time of the introduction of BBFC, the therapy was modified to a PG/timolol FC and BBFC on 41 eyes, a PG and BBFC on 9 eyes, timolol and $\mathrm{BBFC}$ on 1 eye, and timolol/ pilocarpine FC, a PG and BBFC on 1 eye (Table 2).
The therapy modification (simplification) at the time of the introduction of BBCF made it possible for 50 of the 52 patients to have only three eye drop instillations per day despite the fact that 9 patients used 3 and 41 patients used 4 IOP-lowering molecules. The IOP was $21.2 \pm 3.7 \mathrm{mmHg}$ before, and $16.9 \pm 2.6 \mathrm{mmHg}$, $16.0 \pm 2.2 \mathrm{mmHg}, \quad 17.6 \pm 3.1 \mathrm{mmHg} \quad$ and $18.0 \pm 3.1 \mathrm{mmHg}$ after the introduction of BBFC at month 1, 3, 6 and 12, respectively (Table 3; $p<0.0003$ for all time points compared to baseline, $p=1.0$ for all other comparisons). In the last visit, the IOP was $18.5 \pm 5.0 \mathrm{mmHg}(p<0.0001$ compared to baseline).

Thirty-one patients (59.6\%) experienced no adverse event under BBFC treatment. Seventeen patients $(32.7 \%)$ had ocular and 6 patients $(11.5 \%)$ systemic adverse events (Table 4). None of the adverse events was classified as a serious adverse event. All ocular adverse events were similar: the patients complained about moderate or severe ocular discomfort and some ocular redness; the conjunctiva hyperaemia or conjunctiva and lid hyperaemia was visible on slit lamp examination, but its degree was mild in all cases. The onset of the adverse events ranged between 1 day and 16 months for ocular and 3 days and 11 months for systemic adverse events after the introduction of BBFC. BBFC therapy was terminated on 27 patients $(51.9 \%)$. On 19 patients $(36.5 \%)$, it was terminated due to adverse events. The BBFC therapy was terminated in all 6 patients $(11.5 \%)$ experiencing a systemic adverse event. The ocular
Table 1 Baseline demographics of the patients and study eyes

\begin{tabular}{ll}
\hline Number of patients & 52 \\
Male/female & $27 / 25$ \\
Age (years; mean \pm SD) & $69.3 \pm 10.2$ \\
Type of glaucoma $(n)$ & \\
Primary open-angle glaucoma & 39 \\
Juvenile open-angle glaucoma & 1 \\
Exfoliative glaucoma & 6 \\
Pigment glaucoma & 2 \\
Normal tension glaucoma & 1 \\
Ocular hypertension & 3 \\
Best corrected visual acuity (mean \pm SD) & $0.8 \pm 0.3$ \\
Spherical equivalent (dioptres; mean \pm SD) & $-0.7 \pm 2.4$ \\
Central corneal thickness $(\mu m ;$ mean \pm SD) & $538.5 \pm 29.8$ \\
Vertical cup/dis ratio (mean \pm SD) & $0.9 \pm 0.16$ \\
Octopus visual field mean defect $(d B ;$ mean \pm SD) & $12.8 \pm 7.7$ \\
\hline
\end{tabular}


Table 2 Comparison of the number of daily instillations and the intraocular pressure-lowering ingredients before and after therapy change

\begin{tabular}{|c|c|c|c|}
\hline $\begin{array}{l}\text { Number of daily eye drop } \\
\text { instillations prior to the } \\
\text { introduction of BBFC }\end{array}$ & $\begin{array}{l}\text { IOP-lowering ingredients prior } \\
\text { to the introduction of BBFC } \\
(n=52)\end{array}$ & $\begin{array}{l}\text { Number of daily eye drop } \\
\text { instillations on new medication } \\
\text { containing BBFC }\end{array}$ & $\begin{array}{l}\text { IOP-lowering ingredients in } \\
\text { new medication containing } \\
\text { BBFC }\end{array}$ \\
\hline 1 & $\begin{array}{l}\text { PG }(n=4) \text { PG/timolol fixed } \\
\text { combination }(n=20)\end{array}$ & 1 & None \\
\hline 2 & $\begin{array}{l}\text { Timolol/CAI fixed } \\
\text { combination }(n=1)\end{array}$ & 2 & None \\
\hline 3 & $\begin{array}{l}\text { PG/timolol fixed combination } \\
\text { and CAI }(n=15) \\
\text { PG and CAI }(n=4) \\
\text { Timolol/CAI fixed } \\
\text { combination and PG }(n=4) \\
\text { Timolol/pilocarpine fixed } \\
\text { combination and PG }(n=1) \\
\text { Timolol/brimonidine fixed } \\
\text { combination and PG }(n=1)\end{array}$ & 3 & $\begin{array}{l}\text { PG and BBFC }(n=9) \\
\text { PG/timolol fixed } \\
\text { combination and BBFC } \\
(n=41)\end{array}$ \\
\hline 4 & None & 4 & Timolol and BBFC $(n=1)$ \\
\hline 5 & $\begin{array}{l}\text { Timolol/brimonidine fixed } \\
\text { combination, PG and CAI } \\
(n=2)\end{array}$ & 5 & $\begin{array}{l}\text { PG, timolol/pilocarpine } \\
\text { fixed combination and } \\
\text { BBFC }(n=1)\end{array}$ \\
\hline
\end{tabular}

$B B F C$ brinzolamide/brimonidine fixed combination, $P G$ prostaglandin analogue, $C A I$ topical carbonic anhydrase inhibitor

Table 3 Comparison of under treatment intraocular pressure before and after introduction of the brinzolamide/brimonidine fixed combination (BBFC)

\begin{tabular}{|c|c|c|c|c|c|c|c|}
\hline $\begin{array}{l}\text { Baseline IOP } \\
(\mathrm{mmHg}) \text { on } \\
\text { medication } \\
\text { prior to } \\
\text { introduction } \\
\text { of BBFC }(0)\end{array}$ & $\begin{array}{l}\text { Month } 1 \\
\text { IOP } \\
(\mathrm{mmHg}) \text { on } \\
\text { new } \\
\text { medication } \\
\text { containing } \\
\text { BBFC (1) }\end{array}$ & $\begin{array}{l}\text { Month } 3 \\
\text { IOP } \\
(\mathrm{mmHg}) \text { on } \\
\text { new } \\
\text { medication } \\
\text { containing } \\
\text { BBFC (2) }\end{array}$ & $\begin{array}{l}\begin{array}{l}\text { Month } 6 \\
\text { IOP } \\
(\mathrm{mmHg}) \text { on }\end{array} \\
\text { new } \\
\text { medication } \\
\text { containing } \\
\text { BBFC (3) }\end{array}$ & $\begin{array}{l}\text { Month } 12 \\
\text { IOP } \\
(\mathrm{mmHg}) \text { on } \\
\text { new } \\
\text { medication } \\
\text { containing } \\
\text { BBFC (4) }\end{array}$ & $\begin{array}{l}\text { Last visit } \\
\text { IOP } \\
(\mathrm{mmHg}) \text { on } \\
\text { new } \\
\text { medication } \\
\text { containing } \\
\text { BBFC }\end{array}$ & $p$ value* & $p$ value* \\
\hline$n=50$ & $n=39$ & $n=28$ & $n=25$ & $n=23$ & $n=50$ & & \\
\hline $21.2 \pm 3.7$ & $16.9 \pm 2.6$ & $16.0 \pm 2.2$ & $17.6 \pm 3.1$ & $18.0 \pm 3.1$ & $18.5 \pm 5.0$ & $\begin{array}{l}p_{\text {Ovs. } 1,2,3,4} \leq 0.0003 \\
p_{1 \mathrm{vs} .2}=1.0 \\
p_{2 \mathrm{vs} .3}=1.0 \\
p_{3 \mathrm{vs} .4}=1.0 \\
p_{2 \mathrm{vs} .4}=1.0 \\
p_{3 \mathrm{vs} .1}=1.0\end{array}$ & $p_{\text {Ovs. last visit }}<0.0001$ \\
\hline
\end{tabular}

*Paired $t$ test with Bonferroni corrected $p$ values

adverse events led to termination in 13 patients $(25.0 \%)$. In 8 patients $(15.4 \%)$, BBFC therapy was terminated due to insufficient IOP reduction. In these cases, glaucoma surgery was performed.

\section{Discussion}

In the current investigation, we evaluated the IOPlowering efficacy and tolerance of BBFC on open- 
Table 4 Summary of adverse events related to the brinzolamide/brimonidine fixed combination

\begin{tabular}{ll}
\hline Study population & 52 \\
Patients with no adverse event & $31(59.6 \%)$ \\
Patients with any adverse event & $21(40.3 \%)$ \\
Ocular adverse events (ocular discomfort and some ocular redness) & $17(32.7 \%)$ \\
Systemic adverse events & $6(11.5 \%)$ \\
Systemic arterial hypotension & $3(5.8 \%)$ \\
Tachycardia & $1(1.9 \%)$ \\
Dry mouth and chest pain & $1(1.9 \%)$ \\
Sleep disorder & $1(1.9 \%)$ \\
\hline
\end{tabular}

angle glaucoma and ocular hypertension eyes which required complex glaucoma medication. The study population comprised all our patients who received at least one instillation of BBFC during the first 28 months after BBFC was introduced in Hungary. In contrast to the previous studies in which BBFC was used as a stand-alone medication [7-15] or an adjunctive medication to PGs [16-18], our investigation reflects real-life clinical experience. Almost all our patients were difficult to control open-angle glaucoma cases on different complex topical medications with advanced disc damage and poor IOP control. In clinical practice, such cases represent a real challenge for the ophthalmologists, and the existing literature on BBFC provides minimal information on the usefulness of BBFC on such eyes. Despite the inhomogeneity of the topical treatment used before BBFC was introduced, we were able to draw useful conclusions from our results.

First, when BBFC was introduced, a major change in the complex topical therapy was also performed. This made it possible to introduce BBFC but at the same time not to increase the number of the daily eye drop instillations to a level that would negatively influence the adherence. In fact, it was possible to apply 3 or 4 IOP-lowering molecules via 3 drop instillations day per in 50 of the 52 patients while the number of daily instillations ranged between 1 and 5 before the therapy change.

Second, we experienced a favourable IOP reduction in the modified therapy containing BBFC. Compared to the baseline IOP on medication $(21.2 \pm 3.7 \mathrm{mmHg})$, the new therapy provided a mean IOP reduction of approximately 3.2 to $5.2 \mathrm{mmHg}$ ( 15.1 to $24.5 \%$ ) during the study period, which is clinically meaningful. The IOP early after treatment modification (at month 1) was
$16.9 \pm 2.6 \mathrm{mmHg}$, and at month 12 it was $18.0 \pm 3.1 \mathrm{mmHg}$. When the treatment effect was evaluated for the individual patients considering their individual target IOP values, the favourable effect was confirmed: the target IOP was not reached in only 8 patients $(15.4 \%)$. We think that the favourable IOP reduction was caused both by the rationalization of treatment and by the additional IOP reduction induced by BBFC.

Third, our experience with the BBFC-related adverse events is somewhat different compared to the data published in short-term studies in which BBFC was a stand-alone medication or was added to a PG therapy [7-22]. In our investigation, $40.3 \%$ of the patients experienced at least one adverse event. Most of these patients experienced ocular adverse events (32.7\% of the total population), which in all cases comprised moderate or severe ocular discomfort, and redness reported by the patients, though only mild ocular hyperaemia was revealed by slit lamp examination. No corneal adverse event was seen. Interestingly, in the published studies, the adverse event frequencies are given in detail for several adverse event categories, separately, but no global adverse event frequency is provided for all ocular adverse events. Therefore, no direct comparison of our current results with the published data is possible. However, if the published adverse event frequencies given for all ocular adverse event categories are summed, the total figure is rather similar to that of the current study. Though this calculation is not scientifically correct (one patient can experience more than one adverse event), one may speculate that the high frequency of BBFC-related adverse events in the current investigation is not extraordinary. The clinically important question raised by the relatively high adverse event frequency in our study is whether eyes on complex 
topical medication are more prone to topical adverse events caused by BBFC than the treatment naive or after washout eyes. This question, however, cannot be answered without further investigations. The length of the period investigated in the current study (mean treatment period 12.8 month) is greater than that in the prospective BBFC studies. This may also play a role in the relatively high frequency of adverse events. Systemic adverse events appeared in $11.5 \%$ of the patients and comprised well-known systemic adverse events associated with brimonidine: systemic arterial hypotension, tachycardia, dry mouth and sleep disorder. Termination of BBFC therapy due to adverse events occurred in $36.5 \%$ of the patients, which underlines the importance of adverse events in BBFC users.

Our study has limitations due to its retrospective and single-centre nature and the lack of a standardized measure for ocular adverse event severity. All IOP measurements were made in the morning hours. Therefore, the 24-h IOP-lowering effect of BBFC was not investigated.

In conclusion, our results show that BBFC can be usefully applied on difficult to control open-angle glaucoma and ocular hypertension eyes that require complex topical medication. A clinically meaningful IOP reduction was reached on the majority of the eyes. However, we also found that BBFC-related adverse events are common. In our study, they led to termination of BBFC therapy in more than one third of the patients. This suggests that in routine clinical practice, clinicians need to count with a considerable percentage of BBFC treatment terminations.

Acknowledgements Open access funding provided by Semmelweis University (SE).

Funding No financial support was received for this submission.

\section{Compliance with ethical standards}

Conflict of interest Gábor Holló received speaker honoraria from Mundipharma, Novartis and Santen. Péter Kóthy received speaker honoraria from Novartis and Santen.

Ethical approval All procedures performed in studies involving human participants were in accordance with the ethical standards of the institutional and/or national research committee and with the 1964 Helsinki declaration and its later amendments or comparable ethical standards.
Open Access This article is distributed under the terms of the Creative Commons Attribution 4.0 International License (http:// creativecommons.org/licenses/by/4.0/), which permits unrestricted use, distribution, and reproduction in any medium, provided you give appropriate credit to the original author(s) and the source, provide a link to the Creative Commons license, and indicate if changes were made.

\section{References}

1. European Glaucoma Society. Terminology and guidelines for glaucoma. 4th ed. Savona: Publicomm, 2014, pp 129-191. ISBN 978-88-98320-05-9

2. Kass MA, Heuer DK, Higginbotham EJ et al (2002) The ocular hypertension treatment study: a randomized trial determines that topical ocular hypotensive medication delays or prevents the onset of primary open-angle glaucoma. Arch Ophthalmol 120(6):701-713

3. Holló G, Katsanos A, Konstas AG (2015) Management of exfoliative glaucoma: challenges and solutions. Clin Ophthalmol 9:907-919. https://doi.org/10.2147/OPTH.S77570

4. Topouzis F, Harris A, Wilson MR et al (2009) Increased likelihood of glaucoma at the same screening intraocular pressure in subjects with pseudoexfoliation: the Thessaloniki Eye Study. Am J Ophthalmol 148(4):606-613. https://doi.org/10.1016/j.ajo.2009.03.024

5. Holló G, Katsanos K, Boboridis KG et al (2018) Preservative-free prostaglandin analogs and prostaglandin/timolol fixed combinations in the treatment of glaucoma: efficacy, safety and potential advantages. Drugs 78(1):39-64. https:// doi.org/10.1007/s40265-017-0843-9

6. Holló G, Topouzis F, Fechtner RD (2014) Fixed-combination intraocular pressure-lowering therapy for glaucoma and ocular hypertension: advantages in clinical practice. Expert Opin Pharmacother 15(12):1737-1747. https://doi.org/10. 1517/14656566.2014.936850

7. Sharma S, Trikha S, Perera SA et al (2015) Clinical effectiveness of brinzolamide $1 \%$-brimonidine $0.2 \%$ fixed combination for primary open-angle glaucoma and ocular hypertension. Clin Ophthalmol 9:2201-2207. https://doi. org/10.2147/opth.s72380

8. Realini T, Nguyen QH, Katz G et al (2013) Fixed-combination brinzolamide $1 \%$ /brimonidine $0.2 \%$ vs. monotherapy with brinzolamide or brimonidine in patients with openangle glaucoma or ocular hypertension: results of a pooled analysis of two phase 3 studies. Eye 27(7):841-847. https:// doi.org/10.1038/eye.2013.83

9. Nguyen QH, McMenemy MG, Realini T et al (2013) Phase 3 randomized 3-month trial with an ongoing 3-month safety extension of fixed-combination brinzolamide $1 \%$ /brimonidine 0.2\%. J Ocul Pharmacol Ther 29(3):290-297. https:// doi.org/10.1089/jop.2012.0235

10. Katz G, Dubiner H, Samples J et al (2013) Three-month randomized trial of fixed-combination brinzolamide, $1 \%$, and brimonidine, $0.2 \%$. JAMA Ophthalmol 131(6):724-730. https://doi.org/10.1001/jamaophthalmol. 2013.188

11. Aung T, Laganovska G, Hernandez Paredes TJ et al (2014) Twice-daily brinzolamide/brimonidine fixed combination 
versus brinzolamide or brimonidine in open-angle glaucoma or ocular hypertension. Ophthalmology 121(12):2348-2355. https://doi.org/10.1016/j.ophtha.2014. 06.022

12. Gandolfi SA, Lim J, Sanseau AC et al (2014) Randomized trial of brinzolamide/brimonidine versus brinzolamide plus brimonidine for open-angle glaucoma or ocular hypertension. Adv Ther 31(12):1213-1227. https://doi.org/10.1007/ s12325-014-0168-y

13. Whitson JT, Realini T, Nguyen QH et al (2013) Six-month results from a phase III randomized trial of fixed-combination brinzolamide $1 \%+$ brimonidine $0.2 \%$ versus brinzolamide or brimonidine monotherapy in glaucoma or ocular hypertension. Clin Ophthalmol. 7:1053-1060. https://doi.org/10.2147/opth.s46881

14. Kozobolis V, Panos GD, Konstantinidis A et al (2017) Comparison of dorzolamide/timolol vs. brinzolamide/brimonidine fixed combination therapy in the management of primary open-angle glaucoma. Eur J Ophthalmol 27(2):160-163. https://doi.org/10.5301/ejo.5000826

15. Weinreb RN, Bacharach J, Fechtner RD et al (2019) 24-hour intraocular pressure control with fixed-dose combination brinzolamide $1 \%$ /brimonidine $0.2 \%$ : a multicenter, randomized trial. Ophthalmology 126:1095-1104. https://doi. org/10.1016/j.ophtha.2018.10.040

16. Feldman RM, Katz G, McMenemy M et al (2016) A randomized trial of fixed-dose combination brinzolamide $1 \%$ / brimonidine $0.2 \%$ as adjunctive therapy to travoprost 0.004 . Am J Ophthalmol 165:188-197. https://doi.org/10.1016/j. ajo.2016.02.026

17. Fechtner RD, Myers JS, Hubatsch DA et al (2016) Ocular hypotensive effect of fixed-combination brinzolamide/ brimonidine adjunctive to a prostaglandin analog: a randomized clinical trial. Eye 30(10):1343-1350. https://doi. org/10.1038/eye.2016.126

18. Lo JS, Pang PM, Lo SC (2016) Efficacy and tolerability of brinzolamide/brimonidine suspension and prostaglandin analogs in patients previously treated with dorzolamide/timolol solution and prostaglandin analogs. Clin Ophthalmol 10:583-586. https://doi.org/10.2147/OPTH.S98607

19. Jin SW, Lee SM (2018) The efficacy and safety of the fixed combination of brinzolamide $1 \%$ and brimonidine $0.2 \%$ in normal tension glaucoma: an 18-month retrospective study. J Ocul Pharmacol Ther 34(3):274-279. https://doi.org/10. 1089/jop.2017.0075

20. Moosavi R, Ansari E (2018) Brinzolamide/brimonidine fixed combination: simplifying glaucoma treatment regimens. Ophthalmol Ther 7:397-403. https://doi.org/10.1007/ s40123-018-0150-x

21. Chew SK, Skalicky SE, Goldberg I (2014) Brinzolamide plus brimonidine for the treatment of glaucoma: an update. Expert Opin Pharmacother 15(16):2461-2471. https://doi. org/10.1517/14656566.2014.966689

22. Nguyen QH (2014) Combination of brinzolamide and brimonidine for glaucoma and ocular hypertension: critical appraisal and patient focus. Patient Prefer Adherence 8:853-864. https://doi.org/10.2147/PPA.S53162

Publisher's Note Springer Nature remains neutral with regard to jurisdictional claims in published maps and institutional affiliations. 